\title{
CARACTERIZAÇÃo DO PERFIL LOGÍSTICO DE ESCOAMENTO DE GRÃOS DE UMA CIDADE DO INTERIOR DO RIO GRANDE DO SUL
}

\section{CHARACTERIZATION OF LOGISTICAL PROFILE FLOW OF GRAIN FROM A COUNTRY TOWN IN RIO GRANDE DO SUL}

\author{
Juliano Nunes Alves ${ }^{1}$ \\ Leander Luiz Klein ${ }^{2}$ \\ Viviane Flaviano ${ }^{3}$ \\ Juliana Mayumi Nishi ${ }^{3}$
}

RESUMO: O sistema logístico desempenha um papel fundamental para o avanço e desenvolvimento de uma empresa, de uma região e de um país como um todo. Esse sistema envolve atividades, como o armazenamento, o transporte e a distribuição dos produtos, o monitoramento das operações e gerenciamento de informações relacionadas. Nesse contexto, o presente trabalho tem como objetivo caracterizar o perfil logístico de uma cidade localizada no noroeste do estado do Rio Grande do Sul. O presente trabalho foi desenvolvido por meio de uma pesquisa bibliográfica e documental com um exame de arquivos, como, por exemplo: Boletins do IBGE, mapas de rotas de transportes rodo ferroviárias municipais, bem como, de entrevistas semiestruturadas com empresários envolvidos no setor de agronegócios. Como resultados, verificou-se a predominância do modal rodoviário e da limitação do modal ferroviário. Em relação à dificuldade de acesso a algumas propriedades, devido à precariedade da malha rodoviária e da falta de suporte governamental, contribui para que os maiores produtores passem a investir em estrutura própria de armazenamento de grãos. Uma proposição da presente pesquisa está no fato de que, se for realizado algum investimento nas rodovias do interior da cidade, poderá contribuir para uma agilidade do escoamento.

Palavras-chave: logística; escoamento de grãos; perfil logístico; estrutura de transportes.

ABSTRACT: The logistics system plays a key role in the advancement and development of a company in a region and a country as a whole. This system involves activities such as storage, transport, and distribution of products, as well as monitoring of operations and managing related information. In this context, this study aims to characterize the profile of logistics of a city in the northwestern part of the state of Rio Grande do Sul. The present work was developed through bibliographical and documentary research with a review of records such as Bulletins of IBGE, maps and transport routes of the municipal railway, as well as semi-structured interviews with managers involved in the agribusiness sector. The predominance of highway transportation and limitation of the railroad was found. The difficulty of access to some properties, because of the precariousness of the road network and lack of government support, has contributed to the larger producers starting to invest in their own structure for storing grain. A proposition of this research is that some investment in the inner city roads could help speed the flow.

Keywords: logistics; grain yield; profile logistics; transportation structure.

\footnotetext{
${ }^{1}$ Doutorando em Administração - Universidade Federal de Santa Maria - UFSM e Professor Titular da Universidade de Cruz Alta - Unicruz. E-mail: admjuliano@yahoo.com.br.

${ }^{2}$ Mestre em Administração - UFSM. E-mail: kleander88@gmail.com.

${ }^{3}$ Mestranda em Administração - UFSM. E-mails: vivianeflaviano@gmail.com; ju_mn5@hotmail.com.
} 


\section{INTRODUÇÃO}

A atividade logística desempenha um papel primordial no desenvolvimento econômico e social, dado que é responsável por assegurar as trocas comerciais entre os vários agentes econômicos, e por abastecer os mercados, satisfazendo as necessidades dos consumidores; com isso, possibilitando um setor logístico competitivo e, ao mesmo tempo, determinante no sucesso econômico da região em que se enquadra, pois o aumento da eficiência do sistema de distribuição leva à diminuição dos custos de transporte, o que se traduz numa redução do custo final dos produtos e reflete em ganhos de competitividade das empresas (MACÁRIO; FILIPE; REIS, 2006).

$\mathrm{Na}$ visão de Fleury, Wanke e Figueiredo (2000), a razão que levou as empresas brasileiras a negligenciarem o processo logístico, ocasionando um atraso de, pelo menos, dez anos em relação aos países mais desenvolvidos, foi o ambiente inflacionário que predominou no país por volta de duas décadas, associado a uma economia fechada e pouco competitiva. Não obstante, o conceito de logística, de acordo com Velangieri (2003), vem assumindo o papel de gestão integrada e estratégica, planejando e coordenando todas as atividades, otimizando todos os recursos disponíveis, buscando o ganho global nos processos operacional e financeiro.

Outra constatação é a de que boa parte das empresas tem uma visão limitada da logística, isto é, vê a logística como o transporte e não dispõe de uma estrutura adequada para administrar seus processos de armazenagem e distribuição. Esse fato, em grande maioria das vezes, acaba gerando excessos de estoques de matériaprima, mau processamento dos pedidos, atrasos nas entregas, entre outros problemas que afetam a confiabilidade da empresa (CIELO; DENUZI; MARTINS, 2005).

Um documento de identificação, caracterização e diagnóstico do perfil logístico de escoamento de grãos da cidade de Cruz Alta foi elaborado com a finalidade de consolidar os dados existentes da cidade e contribuir com futuras pesquisas e dar suporte à elaboração de políticas públicas a serem implementadas, favorecendo os aspectos de competitividade, ressaltando as potencialidades e oportunidades de investimentos por parte do setor privado, para, com isso, elaborarem-se novas ideias e soluções que resultem em novos investimentos na cidade e desenvolvimento econômico e social.

Partindo do pressuposto que o transporte é uma das atividades logísticas comprometidas diretamente com 0 planejamento logístico de negócios que competem em rede e, por isso, é um dos fatores-chave do desempenho dessas cadeias. Mason et al. (2003) relataram estudos empíricos que demonstraram que os custos com o transporte atingem de $2 \%$ a $4 \%$ do faturamento e de $30 \%$ a $60 \%$ dos custos logísticos totais das empresas. Uma forma de obter do transporte maior potencial de contribuição ao planejamento das cadeias e maior agregação do valor é gerenciá-lo de maneira integrada com os processos de suprimento, produção, distribuição e consumo (NIELSEN; TARPY; REEVE, 2003).

O Brasil conta com praticamente a mesma malha ferroviária há oitenta anos, a qual acaba disponibilizando um serviço lento e de pouca produtividade; em relação às rodovias, uma pequena parcela destas 
(apenas cerca de 10\%) são pavimentadas, e a maioria está em precário estado de conservação, segundo levantamentos anuais feitos pela Confederação Nacional dos Transportes (CNT); o desenvolvimento do potencial hidroviário é prejudicado pela localização geográfica dos rios, fora dos principais eixos econômicos e sem comunicação direta com o mar, e pela disseminação de hidroelétricas, sem a devida atenção à construção de eclusas, e o sistema portuário é bastante defasado tecnologicamente, implicando serviços caros e de baixa produtividade (MARTINS, 2001).

Ainda, pode-se afirmar que, no Brasil, um gargalo visível de produtos agrícolas para exportação está relacionado à logística. Sabe-se que o transporte precário da matéria-prima, entre as fontes primárias de produção para a exportação, representa enorme prejuízo para o país. A melhoria das rodovias e do modal ferroviário e o melhor aproveitamento do transporte hidroviário são essenciais e prementes, além do aperfeiçoamento da produtividade dos portos e armazéns. O Brasil perde a competitividade quando o produto agrícola sai pela porteira das propriedades rurais com preços baixos e chega ao destino com custos altíssimos por causa dos problemas logísticos (OMETTO, 2006).

Propõe-se, neste contexto, caracterizar o perfil logístico da cidade e região de Cruz Alta, localizada no estado do Rio Grande do Sul, considerando-se o transporte a partir da estrutura, do desempenho e da logística disponível na visão dos produtores e empresas envolvidas no setor de escoamento da produção agrícola local. A análise terá foco os modais de transporte e o que de diferenciais competitivos a cidade oferece diante dessas carências apresentadas no âmbito nacional em relação à logística e, também, o que precisa ser desenvolvido. Um objetivo específico do estudo, ora concluído, foi caracterizar o perfil da logística de Cruz Alta com base nas entrevistas realizadas com envolvidos no processo. A partir disso, foi possível determinar, sob a ótica deste pesquisador, a demanda existente por uma estrutura adequada para atrair investimentos e profissionais capacitados para atuar no escoamento e melhorar o desempenho logístico. A metodologia utilizada na execução do trabalho, foi realizada de acordo com o plano de atividades abaixo descrito.

\section{FORMULAÇÃO DA BASE DO CONHECIMENTO DO SISTEMA LOGÍSTICO}

As diferentes concepções de logísticas possibilitam a compreensão sobre a complexidade desse termo e suas aplicações nas diferentes áreas de atuação humana. Assim, citam-se palavras de diversos autores para a fundamentação desse tópico. Nas palavras de Novaes (2001, p. 31):

$\mathrm{Na}$ sua origem, o conceito de logística estava essencialmente ligado às operações militares. Ao decidir avançar suas tropas seguindo uma determinada estratégia militar, os generais precisavam ter, sob suas ordens, uma equipe que providenciasse o deslocamento, na hora certa, de munição, viveres, equipamentos de socorro médico para o campo de batalha. Por se tratar de um serviço de apoio, 
sem o glamour de estratégia bélica e sem o prestígio das batalhas ganhas, os grupos logísticos militares trabalhavam quase sempre em silêncio.

$\mathrm{Na}$ concepção de Ching (2001), também, seguindo na mesma linha de Novaes, ressalva que o conceito de logística sempre foi muito utilizado pelas forças armadas. O termo "logística" foi aplicado inicialmente com a tarefa de organizar o suprimento de armas, equipamentos e alimentos às forças armadas distantes.

Complementando os parágrafos acima, para o entendimento de Lovelock (1996), ao longo da história as guerras têm sido ganhas e perdidas por meio do poder e da capacidade logística. Para um dos mais prestigiados grupos norte-americanos de profissionais de logística, o Council of Logistics Management, a logística é definida como:

[...] o processo de planejar, implementar e controlar de maneira eficiente $o$ fluxo e a armazenagem de produtos, bem como os serviços e informações associados, cobrindo desde 0 ponto de origem até o ponto de consumo, com o objetivo de atender aos requisitos do consumidor (NOVAES, 2001, p. 36).

Dessa forma, deve-se considerar entre os fatores logísticos aqueles relacionados com procedimentos de embalagem secundária, transporte, manuseio de carga, armazenagem e disponibilidade de infraestrutura de suporte a essas atividades (CENTRO DE ESTUDOS EM LOGÍSTICA COPPEAD, 2004).

Nas palavras de Ching (2001), a logística inclui todas as atividades de movimentação interna e externa de produtos, envolvendo a troca de bens e serviços por dinheiro ou sem a interveniência deste. Para tanto, é fundamental um sistema de informações e comunicações de dados, visando a maior eficácia e eficiência de atendimento ao consumidor, avançando, assim, do depósito e do pátio da expedição à alta administração tanto de empresas públicas quanto de empresas privadas. Ou seja, é a logística que dá condições reais de garantir a posse do produto, por parte do consumidor, no momento e lugar desejado, ao menor custo possível.

Seguindo a mesma linha de pensamento, Alvarenga e Novaes (2005) salientam que o objetivo da busca de soluções de diferentes tipos de transportes é, por uma ótica, a redução de custos logísticos vinculados ao transporte. De outra visão, a busca de melhorias e soluções de atendimento da demanda, por intermédio do uso de diferentes formas de transportes (BALLOU, 1993; COYLE; BARDI; LANGLEY, 1996; ALVARENGA; NOVAES, 2005; BALLOU, 2006; RUSHTON; CROUCHER; BAKER, 2010). 
Quadro 1: Principais Teorias sobre logística

\begin{tabular}{|c|c|c|}
\hline Componente & Principais Teorias & Autores \\
\hline Objetivo & $\begin{array}{l}\text { A busca de soluções de diferentes tipos de } \\
\text { transportes é, por uma ótica, a redução de custos } \\
\text { logísticos vinculados ao transporte. De outra visão, } \\
\text { a busca de melhorias e soluções de atendimento } \\
\text { da demanda, através do uso de diferentes formas } \\
\text { de transportes. }\end{array}$ & $\begin{array}{l}\text { Coyle, Bardi Et al., 1996; } \\
\text { Ballou; Alvarenga \& } \\
\text { Novaes, Ballou, 1993, } \\
\text { Ballou, 2006; Rushton, } \\
\text { Croucher et al., } 2010 .\end{array}$ \\
\hline $\begin{array}{l}\text { Capacidade } \\
\text { Logística }\end{array}$ & $\begin{array}{l}\text { Ao longo da história as guerras têm sido ganhas e } \\
\text { perdidas por meio do poder e da capacidade } \\
\text { logística. }\end{array}$ & Lovelock (1996). \\
\hline Planejamento & $\begin{array}{l}\text { O processo de planejar, implementar e controlar de } \\
\text { maneira eficiente o fluxo e a armazenagem de } \\
\text { produtos, bem como os serviços e informações } \\
\text { associados, cobrindo desde o ponto de origem até } \\
\text { o ponto de consumo, com o objetivo de atender aos } \\
\text { requisitos do consumidor. }\end{array}$ & Novaes (2001). \\
\hline Atividades & $\begin{array}{l}\text { A logística inclui todas as atividades de } \\
\text { movimentação interna e externa de produtos, } \\
\text { envolvendo a troca de bens e serviços por dinheiro } \\
\text { ou sem a interveniência do mesmo. Para tanto, é } \\
\text { fundamental um sistema de informações e } \\
\text { comunicações de dados, visando maior eficácia e } \\
\text { eficiência de atendimento ao consumidor, } \\
\text { avançando assim do depósito e do pátio da } \\
\text { expedição à alta administração tanto de empresas } \\
\text { públicas quanto de empresas privadas. Ou seja, é } \\
\text { a logística que dá condições reais de garantir a } \\
\text { posse do produto, por parte do consumidor, no } \\
\text { momento e lugar desejado, ao menor custo } \\
\text { possível. }\end{array}$ & Ching (2001). \\
\hline Competitividade & $\begin{array}{l}\text { O termo "logística" foi aplicado inicialmente como a } \\
\text { tarefa de organizar o suprimento de armas, } \\
\text { equipamentos e alimentos às forças armadas } \\
\text { distantes. Ao decidir avançar suas tropas seguindo } \\
\text { uma determinada estratégia militar, os generais } \\
\text { precisavam ter, sob suas ordens, uma equipe que } \\
\text { providenciasse o deslocamento, na hora certa, de } \\
\text { munição, viveres, equipamentos de socorro médico } \\
\text { para o campo de batalha. }\end{array}$ & $\begin{array}{l}\text { Ching (2001); Novaes } \\
(2001) .\end{array}$ \\
\hline
\end{tabular}

Fonte: Elaborado pelos autores (2012).

As teorizações dos autores, que se encontram expostas no quadro, apresentam uma sequência intercomplementar, quanto aos componentes e às concepções; pois indicam, objetivamente, que as soluções demandam planejamentos e requerem diferentes tipos de transportes para a diminuição dos custos e para a satisfação dos clientes. A migração do termo logística, das artes militares para as demais atividades industri- ais, comerciais e de serviços, mostra a importância dessa prática em todos os setores.

\section{PROCEDIMENTOS METODOLÓGICOS}

A pesquisa foi realizada em duas etapas qualitativas subsequentes. Ressalta-se que os estudos de pesquisa qualitativa diferem entre si quanto ao método, à forma e aos objetivos. 
O desenvolvimento de um estudo de pesquisa qualitativa supõe um corte temporal-espacial de determinado fenômeno por parte do pesquisador (NEVES, 1996). Esse corte define o campo e a dimensão em que 0 trabalho a desenvolver-se, isto é, o território a ser mapeado. $O$ trabalho de descrição tem caráter fundamental em um estudo qualitativo, pois é por meio dele que os dados são coletados (MANNING, 1979, p. 668).

A primeira etapa constitui-se em uma pesquisa bibliográfica com concepções e considerações dos autores pesquisados e pesquisa documental com um exame de arquivos, como, por exemplo, Boletins do IBGE, mapas do município de Cruz Alta e de rotas de transportes rodo ferroviárias municipais. Esses documentos receberão interpretação analítica, podendo ser útil para outras pesquisas qualitativas sobre o perfil logístico de transporte de grão em Cruz Alta.

A segunda etapa da pesquisa empírica tem caráter de pesquisa qualitativa, exploratória e descritiva, por envolver relativa escassez de conhecimento na área. Essa etapa, segundo Malhotra (2001), caracteriza-se pela necessidade de estudar o relacionamento e descrever o fenômeno pesquisado. Essa etapa constitui a pesquisa de campo, onde foi levantado um vasto conjunto de dados e informações qualitativas sobre as características da cidade, na visão dos envolvidos. Essas informações foram obtidas por meio da utilização de técnicas de entrevistas diretas com os empresários usuários da estrutura local para o escoamento de grãos, e elas foram necessárias em virtude de peculiaridades locais.

Quanto ao tratamento dos dados, o conjunto de dados e informações coletados durante a pesquisa de campo foi organizado e sistematizado por intermédio de mecanismos computacionais, e analisado pela técnica de análise de conteúdo. Desses procedimentos, resultou o perfil logístico da cidade de Cruz Alta, o qual tornou possível a realização de análises e avaliações sobre as condições e as características desse segmento.

\section{CARACTERÍSTICAS E ANÁLISE DO PERFIL LOGÍSTICO DA CIDADE PESQUISADA}

Com base nos dados e nas informações obtidas, técnicas de análise de conteúdo foram utilizadas para estabelecer, de forma confiável, o perfil logístico da cidade de Cruz Alta. Esse perfil não se referiu somente às características socioeconômicas do segmento, mas, fundamentalmente, ao padrão de estrutura e desempenho logístico da cidade.

É oportuno mencionar que a tarefa de estabelecer um perfil logístico da cidade de Cruz Alta contemplou não apenas a diferença da cidade em relação à região noroeste, mas também suas diferenças e constrastes com o Rio Grande do Sul, em relação ao escoamento pelo porto de Rio Grande, a partir de diferentes modalidades de transporte e suas atividades diretas e indiretas. A análise do perfil logístico de Cruz Alta foi, portanto, efetuada de forma agregada às questões socioeconômicas do município.

\subsection{Considerações sobre 0 setor de transportes e a infraestrutura disponível}

No Estado do Rio Grande do Sul, predomina a modalidade rodoviária de transporte, devido ao fato do transporte ferroviario ser, segundo os entrevistados, muito antigo e ter uma capacidade de utilização 
deficitária a ponto de não suportar a expansão que ocorreu, nos últimos anos, na produtividade das lavouras. Em relação à malha rodoviária, pode ser visualizado também pelos dados do Departamento Autônomo de Estradas e Rodagem (2012), que, no Estado, 7.330,65 km estão pavimentados e 3.863,61 não pavimentados, representando um total de 11.194,26 km e, destes, Cruz Alta possui 456,28 km de estradas pavimentadas ou $6,22 \%$ do total do Estado e 167,26 não pavimentadas ou $4,33 \%$ do total do Estado. Do sistema rodoviário total, na cidade de Cruz Alta, na visão dos produtores, a estrutura é regular a ponto de ser chave a realização de aperfeiçoamentos na pavimentação das principais vias vicinais da cidade que ligam as principais rodovias do escoamento e, também, a falta de acostamento para o deslocamento das novas tecnologias disponíveis entre as propriedades.

No Quadro 2, pode-se verificar, de maneira geral, a distribuição das rodovias no Rio Grande do Sul, bem como suas coincidentes e vicinais.

\begin{tabular}{lc}
\multicolumn{2}{c}{$\begin{array}{c}\text { Quadro } 2 \text { - Rede Rodoviária do Rio } \\
\text { Grande do Sul }\end{array}$} \\
\hline RODOVIAS & KM \\
\hline Federal & $6.212,76$ \\
Acessos federais & 64,30 \\
Estadual & $8.931,78$ \\
Vicinais & 823,83 \\
Estaduais coincidentes & $2.381,48$ \\
Acessos estaduais & 387,19 \\
Travessias urbanas & 137,72 \\
Total & $18.939,06$ \\
\hline Fonte: DEPARTAMENTO AUTÔNOMO DE \\
\multicolumn{2}{c}{ ESTRADAS DE RODAGEM (2012). }
\end{tabular}

Abrangendo a discussão, pode-se afirmar, ainda, que a infraestrutura de transporte disponível no Brasil é significativamente menor do que a existente em diversos países em desenvolvimento e de grandes extensões territoriais. Por exemplo, a densidade ferroviária no Brasil (calculada a partir do número de quilômetros de infraestrutura disponível por cada $\mathrm{km}^{2}$ de área do País) representa $55 \%$ da disponível na China, $40 \%$ da disponível no Canadá e $32 \%$ do México (OJIMA; ROCHA, 2005).

A matriz logística brasileira é composta em $58 \%$ pelo modal rodoviário, enquanto o ferroviário responde por 25\%, segundo o Programa de Aceleração do Crescimento (PAC). Em países como os Estados Unidos, nosso principal concorrente, o modal ferroviário é o principal meio de escoamento. Um comparativo do custo final do produto exportado para a China pelos dois países revela que estamos em desvantagem competitiva.

Por sua vez, as linhas principais e os ramais que compõem a malha ferroviária gaúcha administrados pela América Latina Logística do Brasil S. A. podem ser visualizados na Fig. 2, a qual administra uma malha ferroviária utilizada para o transporte de cargas. A maior parte apresenta bitola de 1 metro, sendo que apenas $5 \mathrm{~km}$ apresentam bitola mista $(1,435 \mathrm{~m})$, com objetivo de realizar a integração com as malhas argentinas e uruguaias. 


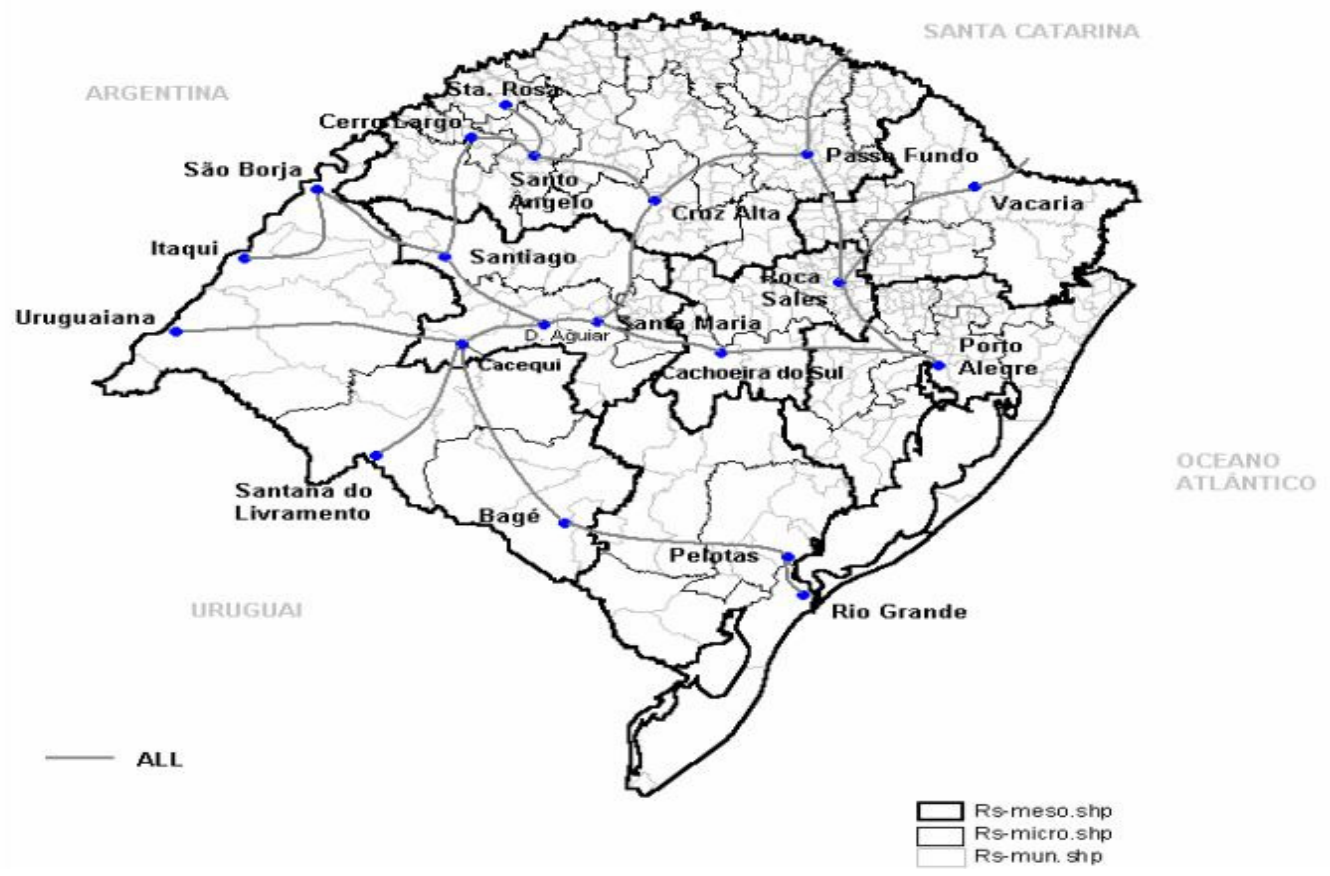

Fig. 1 - Infraestrutura ferroviária no Estado do Rio Grande do Sul. Fonte: BRASIL (2012).

As linhas ferroviárias existentes no Estado são demonstradas na Fig. 1. Como mencionado, as linhas são pertencentes à ALL e cobrem praticamente todas as regiões. Regiões importantes na produção de soja, localizadas ao norte, como Passo Fundo, Santo Ângelo e Cruz Alta, são todas cortadas por linhas férreas, o que facilita 0 transporte ao Porto de Rio Grande, sendo uma alternativa ao transporte rodoviário.

Dessas linhas, atualmente alguns trechos das ferrovias estão sem operação regular e os terminais ferroviários que apresentam maior concentração de cargas localizam-se nas proximidades da Região Metropolitana de Porto Alegre, em Passo Fundo, Cruz Alta e Uruguaiana. O terminal de Cacequi possui uma estrutura diferenciada, pois apresenta um caráter rodoferroviário. Os principais produtos transportados são combustíveis, adubos e soja.

O porto de Rio Grande complementa a infraestrutura de transporte do Estado e também representa uma parcela muito grande no escoamento da produção agrícola do Rio Grande do Sul e, em especial, da Região de Cruz Alta. Nesse contexto, também vale ressaltar que 0 Porto representa, considerando dados do período de 1998 a 2002 , cerca de $95,47 \%$ do total do valor exportado do Estado do Rio Grande do Sul.

Em relação ao escoamento pelo porto de Rio Grande, a Fig. 2 apresenta as principais rodovias federais no Rio Grande do Sul. A BR 392 é a principal rodovia com destino a Rio Grande, e, juntamente com as BR's 285 e 287, formam o principal complexo viário, ligando as principais regiões produtoras de soja do Estado. 


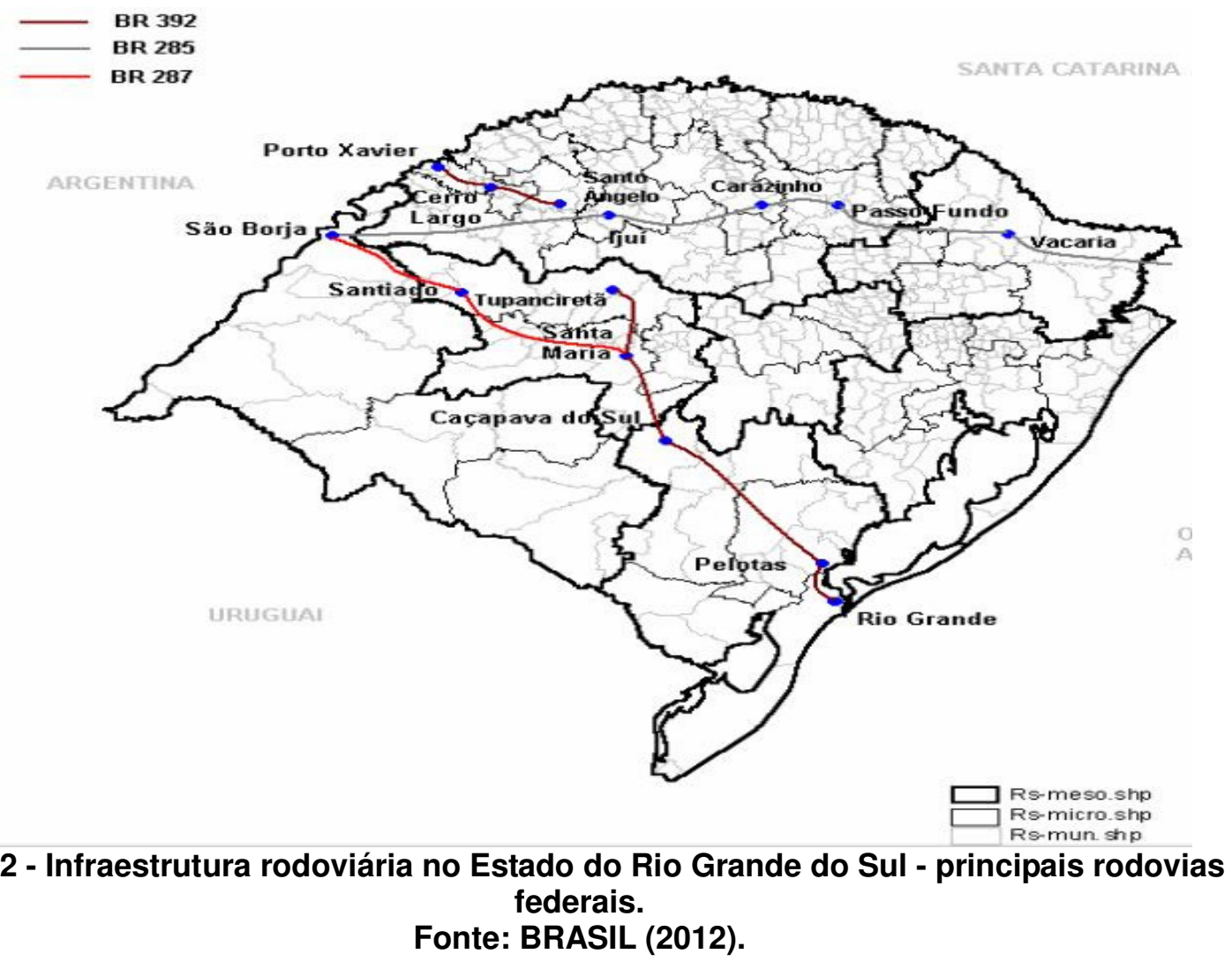

Um fator que deve ser considerado nesse levantamento do perfil logístico está na intermodalidade de grãos. Fator descrito por todos os entrevistados como determinante para 0 desenvolvimento regional e para atração de novos investimentos.

\subsection{Transporte intermodal de grãos na cidade de Cruz Alta}

A importância da análise da opção intermodal está na perspectiva mais ampla, que tem norteado $o$ planejamento de transportes das nações, de redução de custos em busca da competitividade nos mercados internacionais. Conforme Lieb (1978), por causa de características diferentes entre os modais alternativos, como custos e outros aspectos qualitativos, pode ser economicamente desejável que, entre a origem e o destino de uma determinada mercadoria, se lance mão de mais de uma modalidade de transporte, utilizando as vantagens inerentes a cada uma delas, o que resulta em serviço de menor custo e/ou de melhor qualidade.

A complementação entre as modalidades de transporte envolvidas num sistema intermodal implicará atividades de transbordo, isto é, recursos humanos e equipamentos para transferir as mercadorias de um meio de transporte para outro. Segundo Novaes (1989), na formulação do problema de transbordo, a diferença básica com relação ao modelo anterior é que regiões produtoras e consumidoras também possam participar com relevantes volumes relativos às atividades de transbordo. Nesse sentido, pode-se até chegar à situação de uma região inexpressiva, em termos de produção e consumo, transformar-se em 
importante centro de transferência intermodal de mercadorias. No caso deste estudo, isso não se percebe, pois Cruz Alta está posicionada em uma região onde está a maior concentração de produtores do Estado, além disso também é estrategicamente a cidade mais bem posicionada, em relação ao escoamento, por ter o trânsito de toda região noroeste e também 0 entroncamento da malha ferroviária na cidade.

O modelo para a avaliação da alternativa de transporte de custo mínimo para o transporte de grãos no Estado do Rio Grande do Sul, acrescido das alternativas intermodais, pode ser feitos em dois níveis distintos. No primeiro, na perspectiva do usuário, pode-se determinar o percurso de custo mínimo para as rotas. Noutro nível, desenvolver a análise de sensibilidade dos fretes intermodais, com o objetivo de identificar seus níveis de competitividade na perspectiva da racionalidade do modelo, que é a distribuição entre as modalidades que minimizam o custo total de transporte, na condição ceteris paribus, isto é, quando apenas o valor do frete intermodal de determinada rota variava.

Cruz Alta mantém algumas características importantes, no que diz respeito aos fluxos de grãos, como já foi dito anteriormente. Por um lado, a região, ao direcionar grande parte de sua produção para o comércio exterior, acaba reforçando a importância da cidade e do seu posicionamento geográfico. Por outro, a presença e instalação de empresas beneficiadoras dos grãos na região trazem fluxos significativos de produtos. Como afirmou um dos entrevistados que se instalou na cidade:

Nossa empresa se instalou na cidade por ser um ponto estratégico para empresa e pela redução dos custos em transporte, pois a grande produção do Estado está localizada aqui, então nada mais viável do que também instalar uma unidade de recebimento e beneficiamento (Entrevistado).

Portanto, a instalação de um Terminal Intermodal Rodoferroviário em Cruz Alta seria um grande atrativo para aumentar a movimentação de contêineres por via férrea, pelo Porto de Rio Grande, trazendo cargas dos principais exportadores da fronteira Oeste e Norte do Estado, expandindo, assim, as operações.

\subsection{A qualidade da infraestrutura}

É provável que a incipiência da discussão sobre a percepção da qualidade da infraestrutura logística à luz da segmentação dos exportadores seja causada por dois elementos principais. O primeiro estaria relacionado a um entendimento mais claro sobre as principais dificuldades logísticas à exportação. Por exemplo, quais fatores constituem, realmente, obstáculos à exportação? Qual a sua importância relativa? $O$ acesso aos portos é mais importante que a movimentação de cargas nos portos ou viceversa? Qual a importância relativa de fatores conjunturais na exportação, como a disponibilidade de navios? Cruz Alta possui estrutura para centralizar as demandas regionais? Mais uma vez, algumas publicações sugerem que, no debate sobre a qualidade da infraestrutura exportadora, estão claras quais seriam as principais dificuldades à exportação. No entanto, não é claro o entendimento sobre quais fatores são prioritários e como eles estão relacionados com os segmentos 
exportadores.

Dos principais problemas encontrados a partir das entrevistas, referem-se: tanto ao acesso quanto à capacidade de transbordo e escoamento do porto de Rio Grande e isso já foi abordado no estudo de Wanke (2004), no qual já se percebia esses problemas, que os exportadores de cargas a granel, basicamente minérios e grãos, consideram como principal dificuldade logística à exportação o escoamento e acesso aos portos. Além dos reduzidos investimentos em infraestrutura física nos últimos anos, esses exportadores também percebem uma sensível piora na burocracia para a exportação. Isso talvez seja reflexo da carência de mecanismos similares às EADIs, que "compensem" as longas filas e tempos de espera no escoamento e acesso de cargas aos portos, decorrentes de deficiências na infraestrutura física.

A restrição do Porto de Rio Grande está na existência apenas de quatro centrais de transbordo, o que dificulta o escoamento, e esse processo, como abordado pelos entrevistados, acabam enviando sua produção apenas quando a "janela do porto abre", o que não é frequente, dificultando a logística e forçando os envolvidos a investir em aumento de capacidade física para não pararem a produção e as negociações.

Nesse sentido, Cruz Alta tem um potencial, como já mencionado anteriormente, extraordinário no ponto em que os maiores produtores da região noroeste estão localizados na cidade e, por outro lado, as indústrias que beneficiam ou industrializam essa produção são poucas. Isso demonstra um potencial para que novas empresas se instalem e, com isso, aumente a oferta para o recebimento da produção e não fique tão dependente dessa chamada janela de exportação.

Já, em relação à qualidade da malha rodoviária em Cruz Alta, pode-se verificar, a partir do Quadro 3, alguns focos levantados pela 5a Superintendência Regional de Cruz Alta do Departamento Autônomo de Estradas de Rodagem - DAER que merecem ser destacados. Outra consideração da malha rodoviária do Rio Grande do Sul diz respeito ao fato de que grande maioria dela é gerenciada pelo governo Federal e Estadual, sendo o caminho para a administração municipal focar na melhoria das vias vicinais, as quais contribuem, significativamente, para 0 desenvolvimento da estrutura de escoamento de Cruz Alta, conforme dados do Quadro 3, e, também, pelas entrevistas com os envolvidos.

Não é possível afirmar, a priori, que outras características dos exportadores, em outras circunstâncias, levariam a um maior peso da operação portuária. O máximo que pode ser afirmado é que as dificuldades ou barreiras à exportação, de modo geral, parecem estar relacionadas à estrutura física do porto para receber navios, para a exportação da produção. 
Quadro 3 - Rede Rodoviária - Região Cruz Alta

\begin{tabular}{|c|c|c|c|c|}
\hline TRECHO & $\begin{array}{l}\text { EXT. } \\
\text { (KM) }\end{array}$ & PROBLEMA & CONSERVAÇÃO & SITUAÇÃO \\
\hline $\begin{array}{l}\text { ENTR. BR-158 (B) (p/ Cruz Alta) - ENTR. } \\
\text { ERS-527 (Tupanciretã) }\end{array}$ & 21,52 & $\begin{array}{l}\text { Desgaste e } \\
\text { sinalização } \\
\text { deficiente }\end{array}$ & Regular & Pavimentada \\
\hline Chiapeta - ENTR. ERS-155 & 16,32 & $\begin{array}{l}\text { Desgaste e } \\
\text { sinalização } \\
\text { deficiente }\end{array}$ & & Pavimentada \\
\hline $\begin{array}{l}\text { ENTR. BR-392 (Santa Tecla) - ENTR. ERS- } \\
533 \text { (Capão do Cipó) }\end{array}$ & 49,77 & $\begin{array}{l}\text { Revestimento em } \\
\text { alguns pontos } \\
\text { desagregado }\end{array}$ & Regular & Pavimentada \\
\hline $\begin{array}{l}\text { ENTR. RSC-377 (Santa Tecla) - ENTR. ERS- } \\
522 \text { (Jóia) }\end{array}$ & 30,26 & $\begin{array}{l}\text { Segmentos sem } \\
\text { restauração }\end{array}$ & Regular & Pavimentada \\
\hline $\begin{array}{l}\text { ENTR. BRS-158 (p/ Cruz Alta) - Acesso a Boa } \\
\text { Vista do Incra }\end{array}$ & 30,03 & Roçada deficiente & Boas condições & Pavimentada \\
\hline $\begin{array}{l}\text { ENTR. com a BRS-285 (p/ljuí) ao ENTR. com } \\
\text { a BRS-468 (p/ Campo Novo) }\end{array}$ & 80,88 & $\begin{array}{l}\text { Desgaste e } \\
\text { sinalização } \\
\text { deficiente }\end{array}$ & Regular & Pavimentada \\
\hline $\begin{array}{l}\text { Acesso ao Aeroporto (Santo Ângelo) - ENTR. } \\
\text { ERS-342 (para Catuípe) }\end{array}$ & 21,68 & $\begin{array}{l}\text { Tráfego em dias } \\
\text { de chuva }\end{array}$ & Rodovia em obras & Em pavimentação \\
\hline $\begin{array}{l}\text { ENTR. com ERS-342 (p/ Catuípe) - ENTR. } \\
\text { com ERS-155 (Chorão) }\end{array}$ & 10,33 & $\begin{array}{l}\text { Rodovia não } \\
\text { pavimentada }\end{array}$ & Boas condições & Não pavimentada \\
\hline $\begin{array}{l}\text { Entrocamento VRS-824 (p/XV de Novembro) - } \\
\text { ENTR. BR-377 (p/ Cruz Alta) }\end{array}$ & 25,80 & $\begin{array}{l}\text { Desgaste e } \\
\text { sinalização } \\
\text { deficiente }\end{array}$ & Boas condições & Pavimentada \\
\hline $\begin{array}{l}\text { Acesso a Catuípe - Entrocamento BRS- } \\
\text { 285(A) (p/ São Luiz Gonzaga) }\end{array}$ & 18,30 & $\begin{array}{l}\text { Sinalização } \\
\text { deficiente }\end{array}$ & Boas condições & Pavimentada \\
\hline $\begin{array}{l}\text { ENTR. com a BR-285/ERS-522 ( } \mathrm{p} / \text { Augusto } \\
\text { Pestana) ao ENTR. com a BR-158/377 ( } / \\
\text { Santa Maria) }\end{array}$ & 44,69 & $\begin{array}{l}\text { Segmentos com } \\
\text { deformação e } \\
\text { sinalização } \\
\text { deficiente }\end{array}$ & Regular & Pavimentada \\
\hline Entr. ERS-342 - Boa Vista do Cadeado & 7,90 & $\begin{array}{l}\text { Em obras e sem } \\
\text { pavimentação }\end{array}$ & Rodovia em obras & $\begin{array}{l}\text { Foi concluída a } \\
\text { camada de } \\
\text { subbase }\end{array}$ \\
\hline $\begin{array}{l}\text { Santa Bárbara do Sul - ENTR. com a BRS- } \\
158 \text { (p/ Cruz Alta) }\end{array}$ & 51,72 & $\begin{array}{l}\text { Sem } \\
\text { pavimentação }\end{array}$ & Boas condições & Não pavimentada \\
\hline $\begin{array}{l}\text { ENTR. com a ERS-223 (Esquina Moser) - } \\
\text { ENTR. com a VRS-824 (p/ XV de Novembro) }\end{array}$ & 20,08 & $\begin{array}{l}\text { Sem } \\
\text { pavimentação }\end{array}$ & Boas condições & Não pavimentada \\
\hline ENTR. BRS-285 (Boa Vista) - Pejuçara & 8,92 & - & Boas condições & Pavimentada \\
\hline Esquina Becker - Ajuricaba & 39,47 & $\begin{array}{l}\text { Sem } \\
\text { pavimentação }\end{array}$ & Regular & Em obras \\
\hline Ajuricaba - ENTR. ERS-155 (Chorão) & 16,91 & $\begin{array}{l}\text { Desgaste e } \\
\text { sinalização } \\
\text { deficiente }\end{array}$ & Boas condições & Pavimentada \\
\hline Chiapeta - Inhacorá & 11,00 & - & Boas condições & Pavimentada \\
\hline $\begin{array}{l}\text { ENTR. BR-392 (Jóia) - ENTR. BR-285/ERS- } \\
342 \text { (p/ ljuí) }\end{array}$ & 35,11 & - & Boas condições & Pavimentada \\
\hline $\begin{array}{l}\text { ENTR. ERS-512 (Pejuçara) - ENTR. BRS-158 } \\
\text { (p/ Cruz Alta) }\end{array}$ & 12,91 & $\begin{array}{l}\text { Sinalização } \\
\text { deficiente }\end{array}$ & Boas condições & Pavimentada \\
\hline $\begin{array}{l}\text { ENTR. com a ERS-510 (Fortaleza dos Valos) - } \\
\text { ENTR. ERS-223 (Ibirubá) }\end{array}$ & 31,04 & Sem acostamento & Boas condições & Pavimentada \\
\hline $\begin{array}{l}\text { Acesso a Boa Vista do Incra - ENTR. VRS- } \\
818(A)(p / \text { Salto do Jacuí) }\end{array}$ & 39,04 & Roçada deficiente & Boas condições & Pavimentada \\
\hline
\end{tabular}

Fonte: Adaptado 5ª Superintendência DAER (2012). 


\subsection{Gargalos do escoamento na cidade de Cruz Alta}

O gargalo para escoar a produção acontece devido ao aumento na produção da soja e ao da colheita do mesmo grão em outros estados, que fizeram crescer a procura por transporte. Por isso, menos caminhões ficam disponíveis e o preço do frete já chegou a subir 15\% em um ano. Hoje, a tonelada custa $\mathrm{R} \$ 55,00$. A transportadora de Júlio Ferreira, em Cruz Alta, noroeste do Rio Grande do Sul, embarca 150 carretas com grãos, por dia, com destino ao Porto de Rio Grande, também no estado gaúcho. Mas a frota é insuficiente para dar conta da demanda. Já, uma das empresas de transportes entrevistada e a empresa prestadora de serviços afirmam que o que dificulta muito o escoamento é a falta de manutenção das rodovias do interior da cidade, como já demonstrado anteriormente com dados do DAER (2012), o que força a utilização de máquinas sucateadas para aguentar os problemas das vias. Uma importante contribuição é que, se forem desenvolvidas as estradas do interior que ligam as propriedades nas principais rodovias, o escoamento será mais eficiente e, principalmente, mais ágil, pois as principais tecnologias iriam para o campo e, por outro lado, os produtores teriam mais acesso ao comércio local. Um exemplo desses problemas é a falta de acostamento para o deslocamento do maquinário, em época de colheita, e dos caminhões no escoamento.

Nesse sentido e na tentativa de driblar a precariedade da infraestrutura, Vitor Marasca adquiriu 15 veículos. Mesmo assim, terá que continuar terceirizando o serviço. O impacto aparece no bolso. Em média, de cada 10 sacas de soja, uma é consumida pelo frete. A saída seria o transporte ferroviário, que, historicamente, custava $10 \%$ a menos, só que o número de vagões é limitado e o preço, agora, equivale ao do rodoviário.

Segundo a América Latina Logística, responsável pelo transporte ferroviário, a empresa trabalha com 350 vagões por dia, o que seria a capacidade do Porto de Rio Grande. Já, o superintendente do Porto, Dirceu Lopes, diz que há espaço suficiente para receber até o dobro do número de vagões que hoje chegam ao local. Isso demonstra uma diferença de opiniões entre os operadores e que favorece, ainda, ao desenvolvimento local como uma alternativa viável para empresas se instalarem e não haver esses gargalos de transporte interior até o porto.

$\mathrm{Se}$ os serviços logísticos não obtiveram o sucesso e o desenvolvimento esperado, no que se refere à infraestrutura para o escoamento de grãos entre os locais produtores e os centros de distribuição, isso implicou em perda de competitividade, para alguns casos, no agronegócio. Os custos são elevados em razão, basicamente, de dois aspectos: (1) à concentração do transporte de mercadorias no modal rodoviário; e (2) à falta de investimentos suficientes, a partir dos anos 1980, para a manutenção e a expansão dos sistemas de transporte em níveis compatíveis com a demanda (CAIXETA FILHO, 2001). Pode-se dizer, também, que essa é uma parcela importante do custo Brasil e, ao mesmo tempo, é reflexo da queda dos investimentos públicos em infraestrutura, pois, embora os custos de transporte sejam relevantes, em qualquer atividade econômica, eles se tornam mais significativos no caso dos produtos agrícolas. Além disso, a variável 
preço é um elemento importante na construção da competitividade de commodities, uma vez que sua importância é reforçada pelos cenários agrícolas atuais, que combinam maior abertura e integração regional (FLEURY; WANKE; FIGUEIREDO, 2000).

Nessa perspectiva, os investimentos em transporte influenciam a localização da atividade econômica e as possíveis melhorias nas suas facilidades permitem unir os fluxos que ligam áreas de produção e consumo, proporcionando novos esquemas de divisão geográfica do trabalho. Tratando, especificamente da estrutura da cidade de Cruz Alta em relação ao desenvolvimento do perfil logístico, os entrevistados abordaram que existe uma necessidade local de hotéis, postos de combustíveis e, principalmente, de aeroporto, para que os investidores tenham acesso à região com agilidade. Foi constatado em um dos entrevistados, no momento em que alegou que as reuniões acabam sendo em outra localidade por problemas de estrutura para a vinda dos gestores, favorecendo a permanência dos envolvidos com o escoamento de grãos e, também, contribuindo para o comércio local.

Dessa forma, mais que exercer influência sobre a localização, uma infraestrutura eficiente de transporte disponível possibilita uma especialização regional, ao permitir atingir mercados mais amplos e mais distantes. Essa função econômica dos transportes tem sido requerida, mais intensamente, nos tempos atuais, em que a globalização imprime uma necessidade de uniformização geral de custos para efeitos de competitividade.

Um outro resultado que os investimentos podem proporcionar é, como destacado por um dos entrevistados: "se tiver acesso adequado às propriedades isso fará não só uma maior eficiência no escoamento mas também irá levar profissionais qualificados para o campo, o que hoje é uma dificuldade de conseguir trabalhadores pelo fato da dificuldades impostas pelas vias."

A partir desse relato, fica claro que uma melhor infraestrutura nas rodovias do interior da cidade proporcionam uma maior especialização da produção ao ter mão-deobra mais qualificada, quanto à agilidade do escoamento, ao ter um transbordo com equipamentos adequados.

\section{CONSIDERAÇÕES FINAIS}

As concepções referenciadas pelos autores possibilitaram a construção de uma base epistemológica sobre os inúmeros elementos conceituais que se organizam na fundamentação do tema e no desenvolvimento da problematização, isto é, na identificação das características do perfil logístico de escoamento de grãos de Cruz Alta - RS.

Para o desenvolvimento do trabalho, destaca-se o envolvimento e a participação das empresas na pesquisa, o que revela, certamente, o interesse e a percepção da categoria quanto às questões associadas à melhoria da logística local. Da mesma forma, também é oportuno revelar a participação das várias modalidades consultadas ao facilitar o trabalho da pesquisa de campo, revelando, da mesma maneira, sua percepção da relevância do problema estudado.

O transporte de commodities, 
especialmente de grãos, é de suma importância para a economia regional, estadual e nacional, por esse motivo, é relevante 0 conhecimento das características dos modais disponíveis, das vantagens e desvantagens de cada um, como os autores indicam. Para tanto, foi indispensável a contribuição dos entrevistados e das informações coletadas em documentos sobre o sistema rodoferroviário entre Cruz Alta e o Porto de Rio Grande e demais pontos de destino dos grãos transportados. O conjunto das informações obtidas nos diferentes trajetos da pesquisa possibilita a caracterização dos modais utilizados pelas empresas pesquisadas em Cruz Alta, para a logística de grãos, como ferroviário e rodoviário. A opção do modal depende do trajeto entre o ponto de origem ao ponto de destino, isto é, da lavoura ao ponto de chegada, que pode ser o Porto de Rio Grande ou as diversas indústrias nacionais de farelo e biodiesel.

As referências pesquisadas e os entrevistados salientam a relevância da intermodalidade como meio facilitador da logística e elemento indispensável aos diferentes trajetos, tanto pela posição geográfica e as distâncias a percorrer das lavouras, das empresas, do porto ou da indústria. Verificou-se, também, a dificuldade de acesso a algumas propriedades, e locais limitados para armazenamento dos grãos, para posterior demanda. O investimento, nas rodovias do interior da cidade, contribui para uma agilidade do escoamento e ter um transbordo adequado.

Consideram-se como elementos limitadores da pesquisa a pouca bibliografia e documentação sobre a produção e transporte de commodities na região pesquisada. Como sugestão para 0 prosseguimento do estudo, considera-se importante abranger o presente estudo para a região noroeste do estado do Rio Grande do Sul, com o objetivo de ter uma visão mais completa a respeito das peculiaridades e demandas existentes pelos investidores e envolvidos com o escoamento da produção agrícola; e monitorar a eficácia, a eficiência e a efetividade de estratégias e políticas públicas a serem adotadas no futuro. $O$ estudo da segurança para o transporte de cargas e a minimização do desperdício de grãos durante o transporte, como elementos de competitividade e lucratividade, em um plano logístico também se faz pertinente, tendo em vista o acelerado desenvolvimento de todos os setores ligados à logística de commodities.

\section{REFERÊNCIAS}

ALVARENGA, A. C.; NOVAES, A. G. N. Logística aplicada. São Paulo: Edgard Blücher, 2005.

ASSOCIAÇÃO NACIONAL DOS EXPORTADORES DE CEREAIS - ANEC. 2006.

- Gerenciamento da cadeia de suprimentos: logística empresarial. São Paulo: Artmed, 2006. ISBN 8536305916.

BELEI, R. A. et al. O uso de entrevista, observação e videogravação em pesquisa qualitativa. Cadernos de Educação. v. 30, p. 187-199, 2008.

BOWERSOX, D. J.; CLOSS, D. J. Logística empresarial: o processo de integração da cadeia de suprimento. Atlas, 2009. ISBN 8522428778 .

BRASIL. MINISTÉRIO DOS TRANSPORTES. Banco de Informações e 
Mapas de Transportes - BIT, 2012. management: efficiency and customer Disponível em: satisfaction. Journal of Operations http://www.transportes.gov.br. Acesso em: 07 Management, v. 20, p. 747-767, 2002 mar. 2012.

CAIXETA-FILHO, J. V. Competitividade do transporte no agribusiness brasileiro. In: GAMEIRO, A. H.; CAIXETA-FILHO, J. V. Transporte e logística em sistemas agroindustriais. São Paulo: Atlas, 2001.

CENTRO DE ESTUDOS EM LOGÍSTICA. A logística enxuta e seus impactos. Cidade Universitária - Ilha do Fundão - Prédio do COPPEAD / UFRJ. Brasil, Rio de Janeiro RJ, 2004.

CHING, H. Y. Gestão de estoques na cadeia de logística integrada. São Paulo: Atlas, 2001.

CIELO, I. D; DENUZI K. F.; MARTINS, R. S. Avaliação da logística como estratégia empresária para pequenas e médias empresas do estado do Paraná (PR). Revista da FAE, v. 8, n. 1, 2005.

COYLE, J. J. et al. The management of business logistics. West, 1992.

COYLE, J. J.; BARDI, E. J.; LANGLEY, C. J. Management of Business Logistics: A Supply Chain Perspective. 6th edition. London: Bookseller, 1996.

DEPARTAMENTO AUTÔNOMO DE ESTRADAS DE RODAGEM (DAER). Condições de trafegabilidade em rodovias, $2012 . \quad$ Disponível em: http://www.daer.rs.gov.br/site/sistema_rodovi ario_trafegabilidade.php. Acesso em: 26 mar. 2012.

FLEURY, P. F.; WANKE, P.; FIGUEIREDO, K. F. Logística Empresarial: a perspectiva brasileira. São Paulo: Atlas, 2000.

HEIKKILÄ, J. From supply to demand chain

LIEB, R.C. Transportation: the domestic system. Reston: Reston publishing, 1978.

LOVELOCK, C. H. Produto mais serviço: vantagem competitiva. São Paulo: Makron Books, 1996.

MACÁRIO, R.; FILIPE, L. N.; REIS, V. Mobilidade urbana sustentável e a distribuição de mercadorias. In: CONGRESSO LUSO BRASILEIRO PARA O PLANEJAMENTO, URBANO, REGIONAL, INTEGRADO E SUSTENTÁVEL - Pluris, 2., 2006. Resumos... Braga: Pluris, 2006.

MALHOTRA, N. K. Pesquisa de marketing: uma orientação aplicada. 3. ed. Porto Alegre: Bookman, 2001. MALHOTRA, N. K. Pesquisa de marketing: uma orientação aplicada. 3. ed. Porto Alegre: Bookman, 2001.

MANFREDINI, C. Intermodais atraem carga de mais valor para trens. Gazeta Mercantil, São Paulo, 08 de julho de 2001.

MANNING, P. K. Metaphors of the field: Varieties of organizational discourse. Administrative Science Quarterly, v. 24, n. 4, p. 660-671, 1979. ISSN 0001-8392.

MARTINS, S. P. A terceirização e o direito do trabalho. São Paulo: Atlas, 2001.

MASON, S. J. et al. Integrating the warehousing and transportation functions of the supply chain. Transportation Research Part E, v. 12, n. 3, p. 141-159, 2003.

NEVES, J. L. Pesquisa qualitativa: características, usos e possibilidades. Caderno de pesquisas em administração, v. 1, n. 3, p. 1-20, 1996.

NIELSEN, R.; TARPY, D. R.; REEVE, H. K. 
Estimating effective paternity number in social insects and the effective number of alleles in a population. Molec. Ecol. v. 12, p. 3157-3164. 2003.

NOVAES, A. G. Sistemas logísticos: transporte, armazenagem e distribuição física de produtos. São Paulo: Edgard Blücher Ltda, 1989.

- Logística e gerenciamento da cadeia de distribuição. Rio de Janeiro: Campus, 2001.

OJIMA, A. L. R. O.; ROCHA, M. B. Desempenho logístico e inserção econômica do agronegócio da soja: as transformações no escoamento da safra. In: CONGRESSO DA SOBER: SOCIEDADE BRASILEIRA DE ECONOMIA E SOCIOLOGIA RURAL, 43., Ribeirão Preto, 2005. Anais.... Brasília: SOBER, 2005.

OLIVEIRA; CAIXETA-FILHO, J. V. Sistema de Informações de Fretes para Cargas Agrícolas: Concepção e Aplicações. Revista Brasileira de Agroinformática, 1997.

OMETTO, J. G. S. Os gargalos da Paulo: Atlas, 2000. agroindústria. O Estado de São Paulo, 22 de maio 2006.

PLANO DE AÇÃO PARA SAFRA DE SOJA 2012 - Porto do Rio Grande. Assessoria de Comunicação Social da SUPRG Superporto de Rio Grande. Disponível em: http://www.portoriogrande.com.br. Acesso em: 01 jun. 2012.

RUSHTON, A.; CROUCHER, P.; BAKER, P. The handbook of logistics and distribution management. London: Kogan Page, 2010. ISBN 0749457147.

VELANGIERI, M. V. Está mudando o perfil das empresas que utilizam logística. 2003 Disponível em: http://www.guiadelogistica.com.br.html.

Acesso em: abr. 2012.

WANKE, P. Impactos da Sofisticação Logística de Empresas Industriais nas Motivações para Terceirização. Revista Gestão \& Produção, Nov 2004

WRIGHT, P.; KROLL, M. J.; PARNELL, J. Administração estratégica: conceitos. São 